\title{
Creating Interopearable e-Portfolios for Different Educational Levels
}

\author{
Sandra Soares and Álvaro Figueira \\ CRACS \& INESC TEC, Faculty of Sciences \\ University of Porto \\ Porto, Portugal \\ sandrapsoares@gmail.com, arf@dcc.fc.up.pt
}

\begin{abstract}
- in this article we present a system capable of creating, managing and presenting digital portfolios. Our system innovates by using roles and states during its creation phase. This allows for high quality elements in the portfolio and promotes the students' reflection over them before full integration. The system also complies with the existing standards for e-portfolios. Moreover, it adds an extension to integrate previous created portfolios from different educational levels. In the article we show the need for such extension and describe how the system deals with integration of such diverse portfolios into a single one.
\end{abstract}

Keywords-Digital Portfolio; e-Portfolio; Interfolio; Interoperability; Migration; Standards.

\section{INTRODUCTION}

Information and Communication Technologies have revolutionized teaching, learning and even personal and interpersonal relations. It is widely accepted that e-learning (and in some cases b-learning) has boosted the use of new tools, with potential to promote an improvement and modernization of education. The e-portfolios, or digital portfolios, have assumed an increasingly important role in this new reality. Albeit e-portfolios have been used increasingly over the last decade in e-learning pedagogical situations, we feel that their use is not yet widely spread amongst different educational levels. Moreover, the e-portfolios are generically used at some stage during the educational period of an individual/student and then left over or, at most, restarted all over again for another educational period.

In this article we describe a system we built (the "Interfolio") which allows students to insert several artifacts (like texts, images/photos, files, links, to describe some) into the system and provide comments to each of these elements. The comments may be made either from the student him/herself, or from another student, or teacher/educator. Degrees of visibility are associated to each element. This feature creates categories of visibility and of access to the contents. The three main pre-defined categories are: owner, teacher and public. Despite having these roles built into the Interfolio, it is possible to define specific roles for each type of user. In our system the organization of each portfolio is temporal and structured by academic levels. This organization aims to give a chronological and evolutional perspective of the portfolio. The developed system also allows the creation of projects, which go through different states until their public release. The notion of pre-publication into intermediate states allows for the creation of moments of discussion (for example between the student and the teacher/tutor) and of intermediate evaluations. These moments promote the discussion of the portfolio/project elements, ultimately leading to an overall improvement of the project's quality.

IMS Global has developed a series of standards for education (LOM being the most well-known). In the case of eportfolios there are already some standards and drafts for goodpractices. Our system uses the standards available as far as possible to allow one institution to import an e-portfolio from another institution. However, as we show in the article, the standard does not offer all is needed to accomplish these job with fully success. Hence, in this article we propose an extension to the IMS standard for e-Portfolios. Yet, the import/export module of the Interfolio is compliant with the standard already available, but augmented with commands that allow the execution of the extension proposed.

Besides the advantages in the educational environment, the digital portfolios also have a very important role in the business. The employer, through the analysis of a digital portfolio, may get an overview of the knowledge and skills of the candidate not depending solely on what appears on his/her resume. We notice however that the motivation for the creation of a digital portfolio can be associated to its eventual integration with an institution or business entity or even with the interoperability between the various entities

\section{BACKGROUND ON E-PORTFOLIOS}

The definition for e-Portfolio for George Lorenzo and John Ittelson [1], is based on the traditional definition of portfolios, which is seen as a folder containing several works, however now stored in digital media. The potential of new technologies allow going much further and the aim is for a digital portfolio that is much more than a group of elements. This idea underlies the words of Helen C. Barret: "the portfolios are not so much a teaching strategy being investigated, but a means to an end: bear reflection that can help students understand their own learning and provide a richer picture of student work documenting their growth over time" [2]. Along with this definition new portfolio elements are introduced: the need to reflect over own work, to learn from previous work, and to 
reflect over comments. It is noteworthy that a portfolio is not necessarily reflective. Portfolios became reflective essentially because we live in a read-write web culture. Yet, the portfolio system must be equipped to enable this functionality.

As important as the projects that are part of the portfolio are the reflection, analysis and self-criticism on the part of the student and comments, reviews and suggestions from evaluators. Thus the portfolio not only the houses what was developed but also the response to several important questions, including: "How was it developed?", "Why was it developed?", "What is the quality that was developed?". Thus not only a portfolio allows a visualization of a finished product but also the entire course of its development. In the literature there are several studies and research work regarding e-portfolios and their reflective behavior. Examples are the studies by Edgerton, Seldin, Wiedmer and Zubizarreta [3][4][5], to name a few.

\section{A. Use of e-portfolios}

In Education, the use of digital portfolios has increased more and more. Whilst the first portfolio examples took the form of static pages only linking information, the recent systems allow also for the storage of comments and interactions between participants. Moreover, the emergence of the ubiquitous web lead to interoperability problems between systems, and therefore digital portfolios took a new development and a new dimension.

In organizational terms, the level of development of the digital portfolio is variable. Figure 1 depicts the stages of organizational development of a digital portfolio (taken from [6]). Increased levels are proportional to increasing concerns that level after level acquires a new dimension: the attention of the author of the portfolio becomes more inclusive and the implementation challenges grow accordingly.

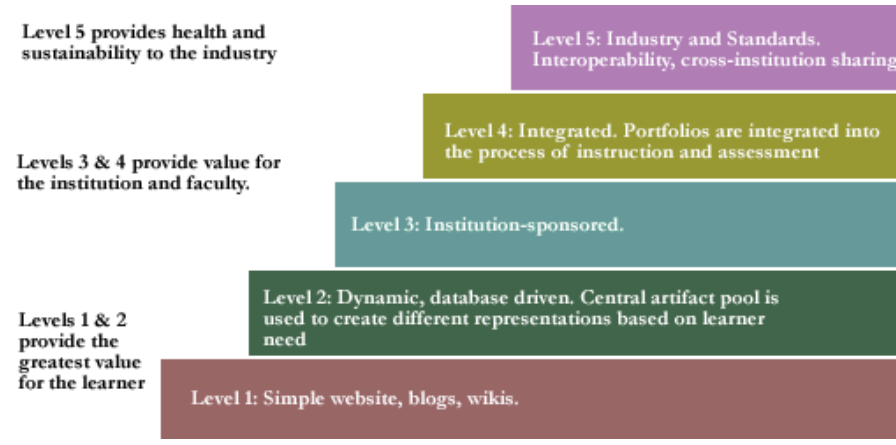

Figure 1. The five levels proposed by Siemens, 2004.

\section{B. Tools for creation of e-portfolios}

In this section we list, describe and reference teaching and learning tools that enable the construction of digital portfolios. The list is far from exhaustive due to space concerns.

\section{a) Mahara}

The Mahara [7] system is an open source tool for digital portfolios. It allows the user to define and to store information which is important, defining accordingly accessibility levels. It is a user centered environment with a permissions framework that provides different views of a digital portfolio for better management. On this platform it is possible to: create a network of friends, have access to reports on the accesses made, control access by managing permissions assigned to groups of individuals (if access is granted, users with this privilege can comment on the evidence available). Comments can be organized in form of a report by user / date.

The Mahara allows to extend the profiles of Moodle, so that students can create their own social networks, friend's lists, online curricula, among other things. When, for example, a potential employer consults the curriculum of a student, it can search the student's history of activities in Moodle, and check the respective academic performance.

\section{b) Elgg}

The Elgg [8], is an open source software that combines the possibilities of a blog with the functions of community sites. This platform enables: creating personal blogs, meet and talk with people; share files (text, pictures, music, videos, movies, etc.), build communities online, create, share and maintain easily information in various formats, including blog posts, upload files, video, audio and comments; users to reflect on and discuss their learning. It also enables integration with Moodle, Blackboard, among others. The level of resources the Elgg provides: User activity; Profile; Notifications; Groups; Blogs; Files soaked; Files; Pages; external pages; Instrument panel; Annotation social; categories; Access.

\section{c) FolioTek}

FolioTek [9] is the result of a project commissioned by the University of Missouri for your degree program and teacher training. The project consisted of the development of three distinct systems management portfolios for three different school programs. Each program had its specific requirements. The differences between each of the programs hindered the development of a system covering all of these needs. With the effort of professionals from different fields, the company created a single software package provided with an adaptive interface. This web application, allows teachers to make the management of student work effectively and efficiently. Students have the opportunity to share comments with other registered members, allowing an improvement in learning.

FolioTek allows students to develop three types of portfolios: a portfolio assessment, which allows them to demonstrate their skills; a "portfolio Scrapbook," which enables a file repository, which is a private portfolio and controlled by the student; a portfolio presentation, where students control their personally customized and accessibility. It is important to note that this software enables integration with Moodle and due to its intuitive interface is easy to use by reducing the need for specific training. It also allows the optimization time by coordinating the organization of documents and integration of messages, tasks and comments to the electronic mail. Since FolioTek does not require the purchase of a server's own institution, its use makes it accessible and reduces the need for technical support.

\section{d) SPD - System of Digital Portfolios}

The SPD2 system was initially developed as part of a Master's dissertation. It is currently an integrated system that enables Internet dissemination of students' work in the scope 
of specific courses [10]. In SPD, a portfolio is built by creating a project, composed of one or more pages, which are based on pre-defined templates [11]. The projects are subject to a set of development states that allow asynchronous evaluation by a jury, in order to filter the best work done and maintain a high level of quality. These states also allow different stages of redesigning and feedback, specific to each page an integral element of the project. We take these ideas in our model and prototype, as well.

\section{e) Conclusion}

Through this short survey we found that, despite having many interesting features, none features and supports the division of the portfolio in educational level, and most do not support interoperability between different systems. We believe this as an important idea as a student starts a portfolio in a given academic level and whenever the student changes the portfolio, or changes educational institution, or even changes the educational level, the portfolio should migrate well from system to system, or adapt itself the new institution, or educational level.

\section{Interoperability}

To facilitate data interoperability, since 2005, an international consortium, the "IMS Global Learning" has developed a set of rules defined in "IMS ePortfolio specification" [12]. These standards were created to enable the interoperability of portfolios across different systems and institutions. The specifications defined in the rules support the advancement of learning in the long term; allow the exchange of portfolios between schools and industry; provide educators and institutions to carry out verification of skills; facilitating the learning experience and improve student development. Depending on the complexity of the digital portfolio, it may contain more or less information and, in many practical applications, certain elements may be unnecessary.

However, there is no doubt that a digital portfolio consists of a diverse set of digital artifacts, related to each other in various ways. This leads to the question: how to organize all the information of a digital portfolio in order to allow their export to another system? This is the central question addressed by the standards of packaging "IMS Learner Information Package (LIP)" and "IMS Content Package (CP)" [13]. Through the packaging process, a digital portfolio is stored within one or more "packages". A package is a structure responsible for aggregating multiple digital artifacts in a single file, preserving your organization

Our study concluded that, while the available standards specified under the Portfolio standards are already capable of providing much functionality for moving a portfolio from a system to another, yet there isn't an innovative system to organize the contents of a portfolio by level of education, nor to adapt themselves to the respective educational level (up to some extent) to the content that is being imported or exported.

\section{THE INTERFOLIO CONCEPTUAL SYSTEM}

\section{A. The conceptual design}

Two-step creation: In the first step the author must fill out a form with information related to the project, such as title, summary, image presentation, discipline, academic year, the type of project and keywords. In the second step the author has the ability to add articles to the project, namely, image files, text, video, music, notes and links. On insertion of each artifact, the author can enter a description about it.

Assessment and visibility: when a teacher assesses a project he/she may take three decisions: accept, reject or request a reformulation. In any of the decisions taken, the teacher records their opinion about the project and, eventually, about each of the artifacts that constitute the project (we borough this methodology from Cesar and Figueira [10]). The projects accepted to be part of the public domain, can be viewed by any user of the system. Registered users are able to comment whole projects, or items.

Import/Export: the system administrator is able to select a project belonging to a portfolio of a registered user, and to export it to another system of digital portfolios; or import it into the current system. The imported portfolio can be edited by its author, or be subject to an assessment, even if it has been assessed in the previous system.

Adaptability: the administrator may insert or update the information in the database and make adjustments to the system corresponding to the level of education. For example by choosing the logo, or the courses available, or even the kind of artifacts that can be inserted into a project.

\section{B. Interoperability issues}

The interoperability of digital portfolios is achieved by setting the portfolio according to the rules of the CP. These standards define a frame of digital elements relating to the digital contents of the portfolio. All the contextual information from a portfolio is also defined within the package. Based on this specification we created a mechanism for the export of portfolios comprising a package of all the information related with the portfolio. For this, multiple queries are made to the portfolio database which retrieves the information necessary for the creation of an XML file (the manifest.xml). In addition to this file, other files (such as files that are part of the projects, comments and ratings) are created as indicated in the rules of the CP. All files are then gathered in one package.

The contents of the file "manifest.xml" defined between the tags <manifest $>$ and $</$ manifest $>$, are illustrated in Listing 1.

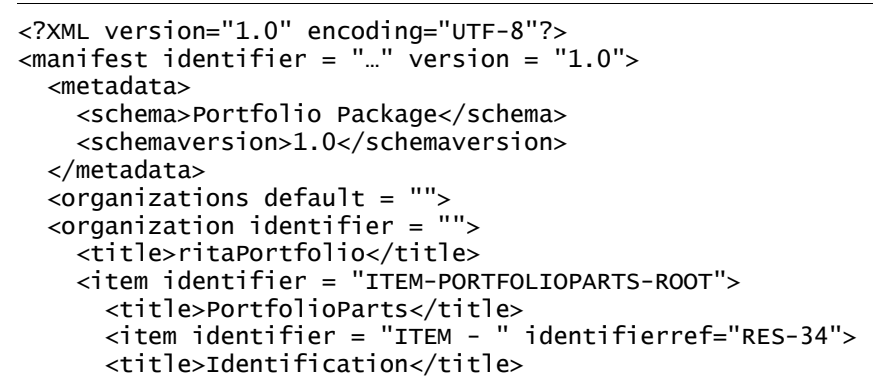




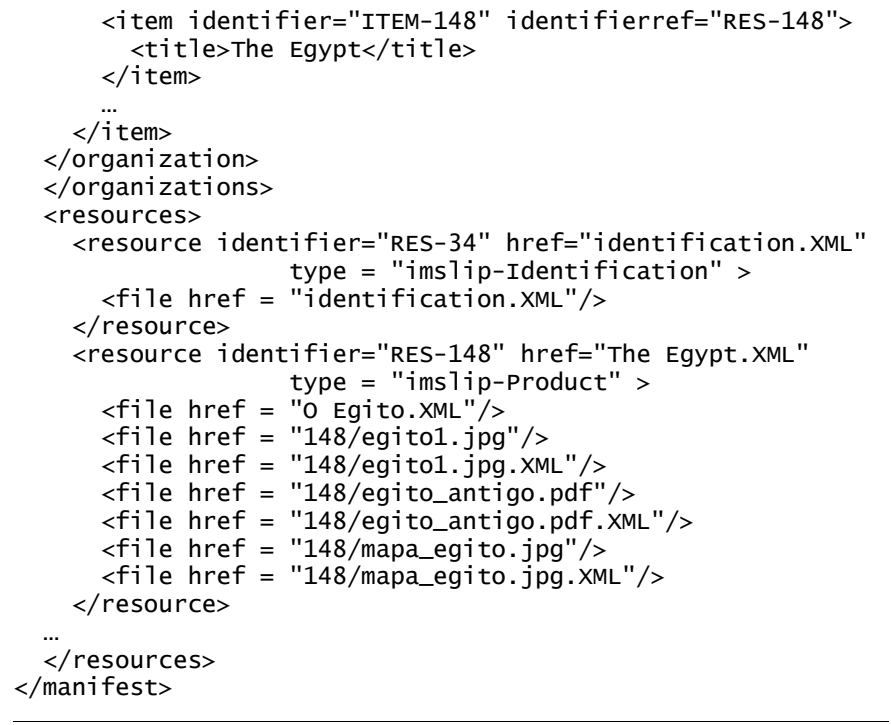

Listing 1. Extract of the manifest.xml file.

The first line begins by defining the version and system file encoding. Following is the main element <manifest> that contains three sub-elements: <metadata>, <organizations> and <resources>. The <metadata $>$ element is optional and provides information about data, in this case used to indicate which file corresponds to a package of a portfolio. The <organizations> element contains information about how the package is organized and can contain multiple elements <Organization>. This zone is used to refer to all components which form part of the portfolio "packaging", using references which will be used later. Each of the elements referenced is placed between the tags $\langle$ item $></$ item $>$ where the parameter value establishes the connection between the components of the portfolio and resources to include.

Each artifact belonging to a project has also associated itself an XML file which stores information about the artifact, particularly when it was inserted and its type. The process of creating the folder's export portfolio, for a given user, is fully automatic. The import of a portfolio is a set up a methodology for converting XML sources into relational databases. This process is performed automatically. A parser reads the XML file and transfers the data to the database for the new system.

\section{DESCRIPTION OF THE SYSTEM}

The Interfolio follows a step-based creation procedure: when a student enters the system he/she can begin to develop a new project, or to further develop an existing project, or even to open a project imported from another system (as illustrated in the UML diagram of Figure 2). The next stage to any of these stages requires the evaluation of the project. In this stage, the project is in a pending state waiting to be assessed by a teacher. In the state assessment, the teacher may refuse the project; accept it, recognizing as valid to be disclosed to the public; or it may require a reformulation which returns the development again to the correspondent previous state. A project may undergo several changes, as indicated by the teacher requests until it is accepted or rejected. All projects submitted for evaluation, whether approved or not, become a teacher's opinion about the project, which is only shared with the author.

The assessment is on its own a reflective procedure allowing the author to perform self-evaluation and to present evidence of progress in the development and reformulation of their projects. Any project that goes into the public domain can be commented upon by registered users. These comments can be viewed by the author of the project, or not, by choice of the reviewer. The author of a project can add comments to his/her own design (and also to the different artifacts that make part of it). It must be noted that comments may serve different purposes: for example to make notes about latter improvements or changes.

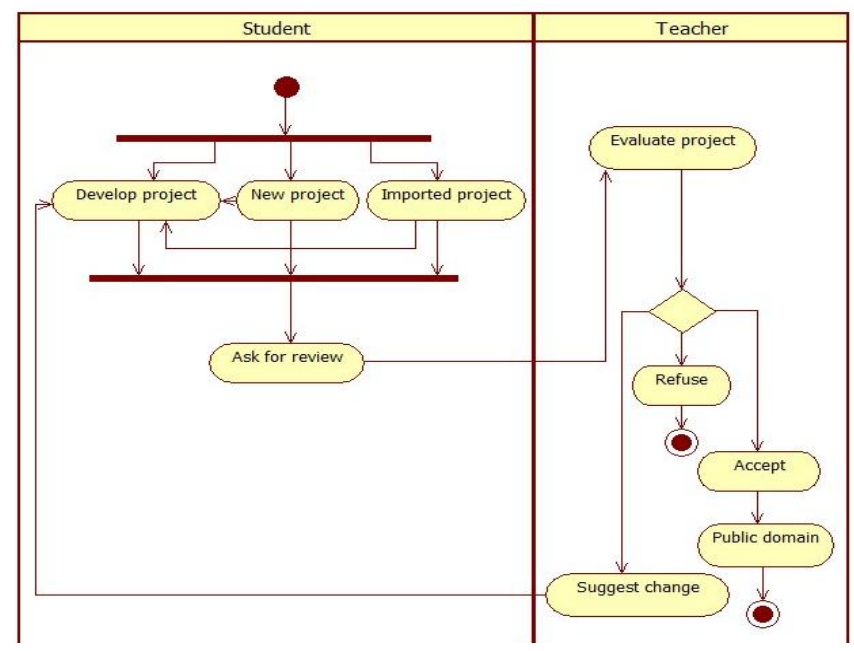

Figure 2. Process for publishing a project.

\section{A. The interface design and implementation}

Our system is web-based and has five main graphical areas, as depicted in Figure 3.

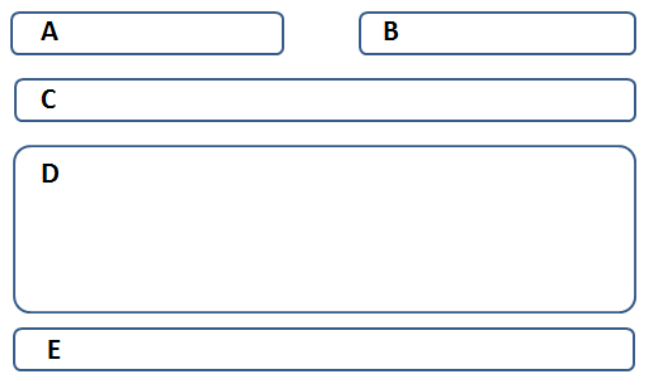

Figure 3. The five zones of the Interfolio system.

Zone A corresponds to the logo area, application name and educational level; zone B is an dynamic area for the different menus corresponding to different types of users; zone $C$ is the area for log and user identification and status; zone $\mathrm{D}$ is where each project is displayed; zone $\mathrm{E}$ is for contact information. In Figure 4 we present an example of project "Statistics" with all the zones above described. 


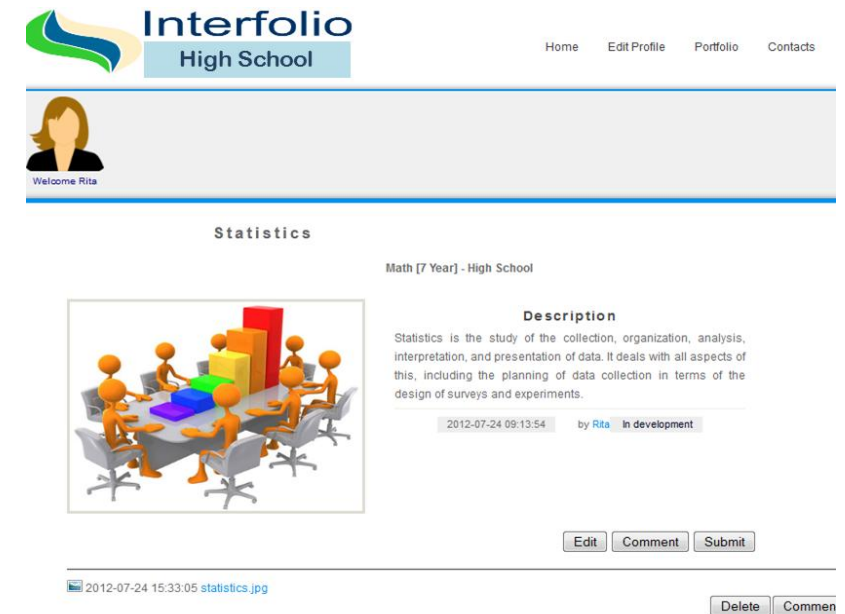

Figure 4. One project in Interfolio.

As referred, the system allows for the inclusion of personal comments either to the whole system, or to a specific item that is part of the project. This situation is illustrated in Figure 5. Note the buttons to comment the whole project or any of the two items linked to it (the image and the text document).

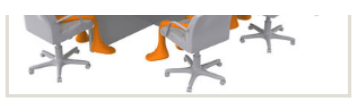

Edit Comment Submit

\begin{tabular}{ll}
\hline 2012-07-24 15:33:05 statistics.jpg & Delete Comm \\
\hline - $2012-07-24$ 09:14:44 Statistics_opinion.docx & Delete Comm \\
\hline
\end{tabular}

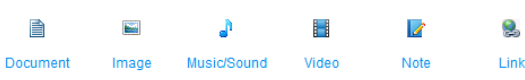

Figure 5. Commenting a project.

In the bottom of the previous figure we also depict the different kind of item available to this educational level. Note that this is a parameterized list by the system administrator. Each educational level may have its own artifacts. Although an author may comment his/her own project, it is also possible to store comments from other registered users. In Figure 6 we show a set of comments made by three users. Note that the visibility has two dimensions: the project or artifact and the degree of visibility.

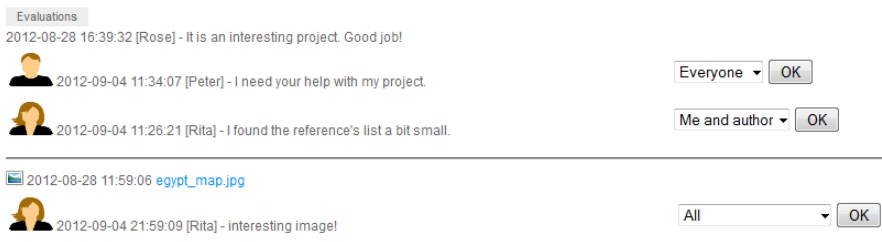

Figure 6. Comments and visibility.

A teacher with privileges may evaluate selected projects. To become an evaluator he/she must be registered and the system administrator must also have conferred that status. When an evaluator authenticates, the system displays in a menu the "Evaluate" option, which in turn displays a list of all the projects submitted for review. Clicking on the project's title or on the associated image the evaluation page appears. On this page (Figure 7) the teacher/evaluator can review the entire contents of the project, the previous assessments, if any, and make the assessment, inserting a general comment on the project or for each of related artifacts.

\begin{tabular}{|c|c|c|c|c|}
\hline & Evaluate & Accept & Refuse & Suggest change \\
\hline 2012-08-29 10:49:30 lusiadas.pdf & & & & Evaluate \\
\hline 2012-08-28 18:40:44 camoes[1].png & & & & Evaluate \\
\hline
\end{tabular}

Figure 7. Evaluation of a project.

The teacher/evaluator has three options: accept the project and make it publicly available; refuse it, or request a set of changes. These options are shown in Figure 7.

\section{CONCLUSIONS}

It is clear that digital portfolios have many educational and pedagogical advantages. Moreover, they should be part of the whole educational (and professional) career, even across different education levels, and different institutions. However, currently available portfolio systems do not allow for this integration and adaption to different of levels of education.

In this context we developed a System for Interoperable Digital Portfolios ("Interfolio") which overcomes these faults: it adaptable to different levels of education and is able to migrate between systems, using the current standards. Besides simple interoperability, our system is able to adapt itself (by configuration) to use the most adequate artifacts for the development of a portfolio in each institution/educational level.

\section{ACKNOWLEDGMENT}

This work is financed by National Funds through the FCTFundação para a Ciência e a Tecnologia (Portuguese Foundation for Science and Technology) within project PEstC/EEI/LA0014/2011.

\section{REFERENCES}

[1] Lorenzo, G., \& Ittelson, J. [Retrieved February, 5 , 2012], from http://www.educause.edu/ir/library/pdf/ELI3001.pdf

[2] Barrett, H. C. (2005). The Research on Portfolios in Education. [Retrieved March, 15, 2012], from: http://electronicportfolios.org/ALI/research.html

[3] Edgerton, R., Hutchings, P., \& Quinlan, K. "The Teaching Portfolio: Capturing the Scholarship in Teaching". American Association for Higher Education, 1991, Washington, DC.

[4] Seldin, P. "The Teaching Portfolio: A Practical Guide to Improved Performance and Promotion/Tenure Decisions", $3^{\text {rd }}$ Edition. Bolton: MA: Anker Publishing Company, Inc. 2007.

[5] Zubizarreta, J. "The learning portfolio: Reflective practice for improving student learning". 2009.

[6] Siemens, G. [Retrieved May 9, 2012], from: http://www.elearnspace.org/Articles/eportfolios.htm

[7] Mahara. [Retrieved February 2012], from http://mahara.org/

[8] Elgg. [Retrieved February 2012], from Elgg: http://elgg.org/index.php

[9] foliotek. [Retrieved February 2012], from http://www.foliotek.com/ 
[10] Félix, C., \& Figueira, Á. "Supervising and managing projects through a template based e-portfolio system". In Proc. of CSEDU. Porto, Portugal. September, 2012.

[11] Figueira, Á., Félix, C., \& Ferreira, C. "An Integrate System for Submission, Assessment, Feedback and Publication of Online Digital Portfolios". Proc. WBE'10. Sharm El-Sheikh, Egypt. 2010.

[12] Smythe, C., Cambridge, D., \& Mckell, M. (2005, 06 02). IMS ePortfolio Information Model. Retrieved 03 12, 2012, from: http://www.imsglobal.org/ep/epv1p0/imsep_infov1p0.html
[13] Smythe, C., Tansey, F., \& Robson, R. (2001, March 9). IMS Learner Information Packaging Information Model Specification, Final Specification, Version 1.0. [Retrieved Abril 12, 2012], from : http://www.imsglobal.org/profiles/lipinfo01.html

[14] Ricardo Queirós and José Paulo Leal and Lino Oliveira and Fernando Moreira, "Integration of ePortfolios in Learning Management Systems", in Computational Science and Its Applications - ICCSA 2011, Springer, LNCS 6786, pp.500-510, 2011. 